\title{
Os fios invisíveis que regem a condição de "aprendiz": uma análise dos enunciados legislativos
}

\section{Janeide Araújo Melo}

Aluna em regime especial da disciplina Análise do Discurso, do Programa de Pós-graduação em Sociologia, UFPE.

\section{Lavínia de Melo XImenes}

Aluna em regime especial da disciplina Análise do Discurso, do Programa de Pós-graduação em Sociologia, UFPE.

Resumo: Este trabalho objetiva analisar os enunciados contidos nas legislaçöes brasileiras referentes à regulamentação da condição de adolescentes "aprendizes". Procurou-se, através da Análise do Discurso, conhecer os significados dos enunciados legislativos. Através das formaçőes discursivas e dos interdiscursos foi possivel perceber os significados subjacentes aos enunciados, elaborados e reelaborados no processo histórico-social. Assim, pode-se ter uma visão menos idilica sobre os discursos "formais", uma vez que estes são permeados por significados, contradiçőes e ideologias.

Palavras-chave: discurso; aprendiz; legislaçôes

\section{Maria Adriana Torres}

Doutoranda em Sociologia, UFPE.
Resumen: Este trabajo tiene como objetivo analizar los enunciados contenidos en la legislación brasileña referentes a la regulación de la condición de los adolescentes "aprendices". Se busca, a través del Análisis del Discurso, conocer los significados de los enunciados de la legislación. A través de las formaciones discursivas y de los interdiscursos fue posible percibir los significados subyacentes a los enunciados, elaborados y reelaborados en el proceso histórico social. Así, puede tenerse una observación menos idílica sobre los discursos " formales ", una vez que, éstos son permeados de significados, contradicciones e ideologías.

Palabras clave. discurso; aprendiz; legislación 



\section{Introdução}

Este ensaio se inscreve no campo da Análise do Discurso (AD) e trata dos processos de significação, procurando entender, através dessa teoria, os enunciados que constituem o sentido de "aprendiz" contido nas legislações brasileiras vinculadas ao segmento infanto-juvenil.

O corpus selecionado para análise diz respeito a um conjunto de leis que regulamentam a condição do "aprendiz", como, por exemplo, o Código de Menores (o de 1927 e o de 1979), a Consolidação das Leis do Trabalho (CLT), de 1943, a Constituição de 1988, o Estatuto da Criança e do Adolescente (ECA), de 1990, e o Decreto no 5.596, de 1 o de maio de dezembro de 2005 , que regulamenta a contratação de "aprendizes" na sociedade brasileira.

O corpus selecionado se constitui a base da análise que empreenderemos, tendo a $\mathrm{AD}$ como teoria norteadora, possibilitando resgatar a memória discursiva constitutiva do conjunto de processos anteriores de produção do sentido, que deixaram suas marcas no contexto do surgimento desses textos legislativos.

As formações discursivas que definem as possibilidades do próprio discurso em um campo aberto de significações proporcionarão uma análise dos enunciados, cerne das questões relacionadas ao "aprendiz", pontuadas no discurso jurídico/estatal. Esta análise possibilitará perceber as questões postas em tais enunciados, ou seja, "o dito" e as questões que os perpassam e constituem seus fios invisiveis, ou seja, o "não-dito", desmistificando as condições de produção do discurso, o cenário histórico e social do contexto imediato e do contexto amplo que dão sentido ao discurso jurídico/ estatal em torno do "aprendiz".

Trata-se de uma análise de enunciados entendida como a performance de um conjunto de regras, articulações que constituem o discurso, como algo que, sem ser definitivo, possui relações com outros discursos. Isto requer que compreendamos os fundamentos teóricos do 
discurso, para perceber que este é produzido em um determinado momento histórico-social e se constitui por sistemas simbólicos que dão materialidade às práticas discursivas dos homens em sociedade, como o caso dos documentos que regulamentam a posição do "aprendiz" no cenário brasileiro.

Esse exercício de aproximação com a $\mathrm{AD}$ nos leva a pensar acerca da importância e da necessidade de questionar e refletir, com maior criticidade, sobre o que lemos, ouvimos e vemos diariamente, assumindo uma atitude menos ingênua em face das diferentes manifestações do discurso, cuja materialidade, não esqueçamos, consiste em apenas uma parte de sua essência.

\section{O discurso e os enunciados}

O discurso é uma materialização das formações discursivas, que são constituídas por uma rede de discursos que são os interdiscursos. São entendidas aquelas como espaço de significação e "determinam o que pode e deve ser dito a partir de uma posição dada numa conjuntura" (PÊCHEUX, 1988, p. 160). É o espaço por onde as palavras se expressam; é a instância através da qual as palavras cumprem sua função, manifestando-se como produto das relações sociais.

O sentido da palavra é constituído no encontro com a realidade, ou seja, na realidade social onde foi produzida. Para Pêcheux, o sentido das palavras não pertence à própria palavra, mas são determinadas pelas posições ideológicas no processo histórico-social. Segundo esse raciocínio, os sentidos das palavras são tecidos por "milhares de fios ideológicos".

Desse modo, as condições de produção discursiva compreendem tanto os sujeitos a situação, como também a memória, o contexto imediato que desenha as circunstâncias da enunciação e, num sentido mais amplo, o contexto sócio-histórico, ideológico.

Quando pensada em relação ao discurso, a memória, com base nos interdiscursos, definidos por meio 
de uma multiplicidade de outros discursos, não-fixos, mantém uma relação com a discursividade atual. Assim, o interdiscurso revela dizeres que remetem à forma como o sujeito significa em uma dada situação discursiva. Aponta para formulações feitas e esquecidas que compõem o cenário do que será dito, "como uma voz sem nome".

A idéia de que o discurso não se origina no sujeito, mas se constitui num processo que é histórico, possibilita entendê-lo tomando por base o encontro entre uma memória (interdiscurso) e uma atualidade (movimento de produção material da vida).

Compete, assim, ao analista do discurso desmistificar o que está por trás do discurso: os sentidos dos enunciados, a posição do sujeito, do interlocutor dando significado à linguagem discursiva no sentido de sua discursividade.

Levando-se em conta que cada enunciado faz parte de um discurso e que cada discurso, por sua vez, está inserido em formações discursivas não-homogêneas, mas heterogêneas, vê-se que cada época, cada momento histórico tem saberes "acatados que se expressam e se preservam sobre o invólucro das palavras, da obra, dos enunciados, das locuções etc." (BAKHTIN, 1992, p. 313). O que se percebe é que "as diferentes formulações de enunciados se reúnem em pontos do dizer, em regiões historicamente determinadas de relações de força de sentidos: as formações discursivas" (ORLANDI, 1992, p. 20).

Os processos discursivos só podem se realizar através das representações que o sujeito dá ao real. Ao produzir o discurso, o sujeito imprime a sua marca, através do qual se identifica como sujeito no mundo.

A dimensão do discurso constitutiva do social possui três efeitos: 1. contribui para a construção do que é referido como identidades sociais e posições de sujeito; 2. contribui para a construção das relações sociais; e 3 . contribui para a construção de sistemas de conhecimento e crenças. 
O discurso se constrói, assim, a partir de um lugar; é constitutivo e constituído nesses e desses processos. Tanto o discurso é determinado pelo processo sóciohistórico como exerce influências sobre ele, havendo, portanto, uma relação dialética. Para Laclau e Mouffe (1990), discurso é um sistema de produção de sentidos; portanto, tudo é discurso. Assim, "[...] todo discurso já é uma fala que fala com outras palavras, através de outras palavras" (ORLANDI, 1992, p. 15).

O desafio está, segundo Orlandi (2001), em escutar o não-dito a partir do dito, entendendo que as palavras não falam por si, mas na conjuntura própria das formações discursivas, através de outras palavras que compõem o discurso, que retrata traços ideológicos em determinado contexto sócio-histórico.

Todo discurso é heterogêneo. Podemos falar de dois tipos de heterogeneidade: a heterogeneidade mostrada e a constituída. A heterogeneidade mostrada diz respeito às citações, aspas, itálicos, notas, aspectos que mostram que o texto não é feito nele mesmo. A heterogeneidade constituída diz respeito à memória do discurso. O discurso possui, portanto, três domínios, antecipação, o previsto, aquilo que ocorre quando se prevê a reação do interlocutor (não no sentido de profecias); memória, vários discursos já ditos em outro lugar; e atualidade, o momento do dizer o que se diz.

Todo discurso como sistema de relações entre significante e significado possui sua materialidade simbolicamente representada pelo texto. Os elementos que contribuem para a produção de sentidos do discurso são a língua, a história, a ideologia. Todo discurso possui as suas condições de produção. Nesse sentido, é fundamental observar o sujeito do discurso, o tempo e o local da produção do discurso, aspectos que ajudam a resgatar a memória discursiva do discurso, possibilitando ao analista ver o sentido das palavras, os enunciados, os discursos transversos, o intradiscurso e os efeitos de sentido, que, segundo Orlandi (1992), se produzem nas relações dos 
sujeitos, dos sentidos inscritos no jogo das formações discursivas, entendidas como diferentes regiões que recortam o interdiscurso e refletem as diferentes posições dos sujeitos, seus lugares sociais. Estes, se representados, constituem sentidos diferentes. O discurso, quer falado, quer escrito, pode provocar mudanças sociais no que concerne a dar voz aos sujeitos, rompendo as relações de poder que sustentam as relações discursivas.

Escutar os dizeres e saberes do sujeito, como propõe a $A D$, implica lançar mão do recurso da interpretação, vista não como decodificação de sentidos, mas como possibilidade de articular as diferentes posições e lugares que o sujeito ocupa na cadeia discursiva.

É esse conjunto de categorias da $\mathrm{AD}$ que possibilitará fazer uma análise dos enunciados legislativos/ estatais no que concerne à produção de sentidos do discurso formal, levando-se em conta os elementos de natureza essencialmente social e jurídica.

\section{O discurso sobre o "aprendiz": dos enunciados legislativos/estatais à produção de sentidos}

A AD tem sido uma abordagem muito utilizada na análise dos discursos político, religioso, da mídia e dos movimentos sociais etc. Entretanto, a produção de textos sobre AD voltada para a análise de documentos jurídicos é escassa. Sabendo que essa teoria pode dar contribuições para perceber os enunciados discursivos e os fios invisíveis que perpassam a sua materialização simbólica, propomos analisar, no âmbito de um corpus de leis brasileiras, o discurso sobre o "aprendiz", posto nos enunciados legislativos/estatais, enfaticamente inserido nos enunciados governamentais contemporâneos, sobre a condição de contratação do segmento infanto-juvenil.

Nesta análise, interessa discutir a questão do "aprendiz", contexto que aponta para diferentes aspectos, como os políticos, os jurídicos e os sociológicos, uma vez que a história do segmento infanto-juvenil "aprendizes" 
se tornou, nas últimas décadas, no Brasil, bastante conhecida. Os enunciados sobre a regulamentação do trabalho do segmento infanto-juvenil "aprendiz", contidos nas leis brasileiras, perpassam um conjunto de interdiscursos em torno de crianças e adolescentes em situação de trabalho. Há uma série de outros discursos que atravessam o texto, entre eles os que associam a condição de "aprendiz" ao processo de socialização, aprendizagem.

Assim, percebemos que o sentido da palavra "aprendiz" traz uma memória que está associada com a aprendizagem vista como ofício de socialização, valor que qualifica uma relação positiva entre mestres e aprendizes, e deixa no imaginário da sociedade uma suposta relação similar à de pais e filhos. O sentido de "aprendiz" implica a noção de que uma é pessoa que aprende um ofício ou arte ou está em processo de aprendizagem. Discursivamente, "aprendiz" é uma palavra inserida em um conjunto de enunciados que fazem parte das legislações governamentais brasileiras, que tomam efeitos de sentidos dentro do processo histórico-social-político-ideológico por que passa a sociedade em cada conjuntura.

A análise da palavra "aprendiz" propicia sua compreensão como o principal signo que registra as mais tênues variações ocorridas nos sistemas ideológicos. Assim, percebemos que a palavra é uma representação do fenômeno em que podemos encontrar as bases ideológicas que ocorrem no processo de comunicação. Para esse entendimento, tomamos de Bakhtin (1999) a reflexão de que a palavra é a matéria essencial da comunicação, que, associada à mensagem dos enunciados legislativos/ estatais da sociedade que os absorve, aceita e também repudia o que está escrito nas leis.

O que se verifica é que todo e qualquer processo discursivo, do mais simples ao mais complexo, apresenta uma cadeia de enunciados que evolui sistematicamente a partir das variadas formações discursivas. "Assim, o discurso escrito é de certa maneira parte integrante de uma discussão ideológica em grande escala: ele responde 
a alguma coisa, refuta, confirma, antecipa as respostas e objeções potenciais, procura apoio, etc." (BAKHTIN, 1999, p. 123).

\section{A análise do corpus}

É no contexto da Revolução Industrial, na Europa, que o discurso sobre o trabalho do "aprendiz" ganha maior visibilidade, uma vez que este passa a dividir com o adulto, nas mesmas condições, a linha de produção nas fábricas e indústrias.

No Brasil, embora também haja registro de "aprendizes" no sistema produtivo desde o final do século XIX, conforme Decreto 1.313 de 1881, que regulamentava então o trabalho das crianças e adolescentes nas fábricas, é somente no início do século XX que a temática ganha relevância em função das políticas públicas que são implementadas em prol do cuidado e proteção da criança e dos adolescentes (FONSECA, 2003, p. 26).

Os primeiros dispositivos legais de proteção ao trabalho infanto-juvenil datam de 1891, com o DecretoLei $n \circ 1.313$, e de 1927, com o Código de Menores, alterado em 1979, quando foi legitimada a passagem de 12 a 14 anos como idade mínima para a inserção no mercado de trabalho; mesmo assim, o Código apresentava arbitrariedade, abandono e violência contra crianças e adolescentes. Desde então, a condição de "aprendiz" era discutida, principalmente, pelos segmentos governamentais que se "preocupavam" em "reajustar" os segmentos considerados "infratores".

A ambigüidade do discurso torna-se evidente quando se identificam não só o esforço para a regulamentação da figura do trabalhador aprendiz como figura jurídica, equiparada a outras categorias de trabalhadores - caso do Código de Menores, de 1927 —, como também a percepção do "aprendiz" considerado pessoa em desenvolvimento e, por conseguinte, diferente das demais categorias, a requerer então uma legislação específica (CLT, 1943). 
O próprio texto legislativo que rege o direito do trabalho no Brasil, constitutivo da CLT, sugere que, para o aprendiz,

[...] o contrato de aprendizagem é o contrato de trabalho especial, ajustado por escrito e por prazo determinado, em que o empregador se compromete a assegurar ao maior de quatorze anos e menor de dezoito anos, inscrito em programa de aprendizagem, formação técnico-profissional metódica, compatível com o seu desenvolvimento físico, moral e psicológico, e o aprendiz a executar, com zelo e diligência as tarefas necessárias a essa formação (CONSOLIDAÇÃO DAS LEIS DO TRABALHO, 1943, art. 428).

Esse enunciado nos permite verificar como outros discursos perpassam o texto: por exemplo, o da proteção social formalizada pelo contrato de trabalho, que prevê o processo de formação do indivíduo, ou seja, uma possível educação formadora da prole do trabalhador que será sucessora deste posteriormente. Lembra que

a estrutura da enunciação e da atividade mental a exprimir são de natureza social. A elaboração estatística da enunciação é de natureza sociológica e a própria cadeia verbal, à qual se reduz em última análise a realidade da língua, é social. Cada elo dessa cadeia é social, assim como toda a dinâmica da sua evolução (BAKHTIN, 1999, p. 122; grifos do autor).

Assim, todo discurso tem uma relação com o que está socialmente posto; nenhum discurso é fixo, mas responde às necessidades históricas concretas e pode se modificar imprimindo novas formas discursivamente situadas no conjunto dos sentidos conjunturais a que se referem.

Quanto à idade para inserção no mundo do trabalho, percebe-se que ela é alterada de 12 anos, idade 
mínima colocada pelo Código de Menores de 1927, para 14 anos, como se confirma a partir de 1943, no enunciado da CLT, reafirmada essa mesma idade pelo Código de Menores, de 1979. A concepção de trabalho com função educativa para o aprendiz vai ganhando corpo e se concretizando a partir da Constituição de 1988, quando aspectos como idade, condições de trabalho e ênfase nas exigências pedagógicas e desenvolvimento integral prevalecem sobre os aspectos produtivos. Essa Constituição enfatiza a "proibição de trabalho noturno, perigoso ou insalubre a menores de 18 (dezoito) e de qualquer trabalho a menores de 16 (dezesseis) anos, salvo na condição de aprendiz, a partir de 14 (quatorze) anos" (CONSTITUIÇÃO BRASILEIRA, 1998, artigo 5 XXXIII). É visível como o enunciado legislativo é contraditório quanto se refere à proibição ao trabalho noturno, "salvo na condição de aprendiz".

A lei vigente atual afirma outra vez a "idade mínima de quatorze anos para admissão ao trabalho" (CONSTITUIÇÃO BRASILEIRA, 1998, artigo 227). O Estatuto da Criança e do Adolescente (ECA) reafirma o conteúdo do artigo 227 da Constituição de 1988 e se constitui na primeira lei aprovada de acordo com a Convenção Internacional dos Direitos das Crianças, de 1989. Legitima: "É proibido qualquer trabalho a menores de quatorze anos de idade, salvo na condição de aprendiz" (ESTATUTO DA CRIANÇA E DO ADOLESCENTE, 1990, Art. 60).

Recentemente, o Decreto no 5.596, de 1 de dezembro de 2005, que regulamenta a contratação de "aprendizes", reafirma a relação jurídica pertinente à contratação desse segmento e afirma, no artigo 2․ capítulo I, que "Aprendiz é o maior de quatorze anos e menor de vinte e quatro anos que celebra contrato de aprendizagem" (BRASIL, 2005).

É importante perceber que a idade se apresenta como uma categoria central do discurso sobre o "aprendiz", uma vez que é através dela que se estabelecem os contratos 
de trabalho. É através dessa categoria que também se percebe a alteração da condição de "aprendiz" até os 24 anos de idade. Isto remete a um discurso que traz em seu contexto uma série de debates em torno da precarização no mundo do trabalho, ou seja, é através de um texto formal que se antecipa, por um lado, o discurso de que se vai dar oportunidades para os jovens se inserirem no mundo do trabalho e aprenderem uma profissão e, por outro, se legitima certa condição de informalidade, uma vez que o contrato de "aprendiz" é temporário, não possui vínculo empregatício, é uma forma discursivamente legitimada pelo Estado a favor do capital, que encontra abertura para se isentar das obrigações pertinentes a contratos de trabalho efetivos, sem prazo determinado. Desse modo, constrói-se para a sociedade, através do discurso, uma visão ideologicamente positiva, nesse sentido, da inserção, proteção e promoção. Na realidade, o que se tem é uma forma de não favorecer o sujeito para o qual as leis deveriam ser feitas.

O mesmo decreto que regulamenta a contratação de "aprendizes" obriga a contratação desse segmento de acordo com o art. 9o, seção I, capítulo IV, como destacamos a seguir:

Os estabelecimentos de qualquer natureza são obrigados a empregar e matricular nos cursos dos Serviços Nacionais de Aprendizagem número de aprendizes equivalente a cinco por cento, no mínimo, e quinze por cento, no máximo, dos trabalhadores existentes em cada estabelecimento, cujas funções demandem formação profissional (BRASIL, 2005).

Desse modo, todas as organizações são obrigadas a contratar "aprendizes"; contudo, o mesmo documento, no art. 14, dispensa da contratação dos "aprendizes", as microempresas e as empresas de pequeno porte e ainda as entidades sem fins lucrativos que tenham como objetivo a educação profissional. 
Ao jovem entre 14 e 18 anos de classe social na qual essa condição de "aprendiz" não é necessária como fonte de renda familiar cabe o lugar de estudante, parecendo não lhe serem necessárias a formação integral tratada anteriormente ou a preparação para o mercado de trabalho. Assim, a preocupação com a formação do "aprendiz" privilegia os jovens que não são beneficiados pelo processo de aprendizagem formal e sistemático das escolas da rede privada de ensino, ou lhes está francamente direcionada. Em geral, estão aí incluídos os jovens das camadas menos favorecidas da população, tanto social como economicamente.

Por outro lado, o Decreto 5.596, em seu art. 79, da seção I, do capítulo III, informa que ao "aprendiz" devem ser garantidos o acesso e a freqüência obrigatória ao ensino fundamental, com horário especial reservado para o exercício das atividades, bem como a capacitação profissional adequada ao mercado de trabalho. Parece que, ao ressaltar que o menor tem a condição de aprendiz, cujo trabalho deve ser realizado dentro da legalidade, 0 documento referido acima deixa nas entrelinhas espaço para pensar na dissociação entre trabalho e aprendizagem.

A configuração da dissociação entre trabalho e aprendizagem remonta às construções ideológicas discursivas que associam, por um lado, trabalho a esforço físico e, por outro, aprendizagem a atividade intelectual, o que reflete o predomínio do pensamento dicotômico nas diferentes esferas da vida e da cultura ocidental. Visto assim o trabalho infanto-juvenil, este expressa a nãopossibilidade de ascensão e crescimento profissional. "Quem estuda tem profissão, quem não estuda trabalha", parece ser uma crença no senso comum.

Tais considerações remetem a outros discursos que envolvem as diferenças sociais e econômicas implicadas na aquisição e construção do conhecimento, no fazer laboral, na concepção de sujeito e cidadão de direito, como se dessa categoria estivessem excluídos as crianças e os adolescentes, por ser identificados como pessoas em formação. 
Entretanto, o Decreto 5.596 foi publicado em um momento em que o desemprego vinha se tornando cada vez mais preocupante em nosso país. Ao mesmo tempo, a exploração da força de trabalho infanto-juvenil ganha cada vez mais espaço na mídia e nos diferentes contextos sociais.

Esse discurso remete a outros, o trabalho passa a ser percebido como etapa de formação do sujeito, sendo ressaltada sua função educativa, de preparação para o mercado e formação integral.

A teoria da proteção integral é a compreensão de que as normas que cuidam de crianças e adolescentes devem concebê-lo como cidadãos plenos, sujeitos, porém, à proteção prioritária por se tratarem de pessoas em desenvolvimento físico, psicológico e moral. (FONSECA, 2003, p. 28).

O discurso norteador da "proteção" da camada infanto-juvenil que trabalha é fundamentado nos princípios da promoção da cidadania de crianças e adolescentes que tem no Estado a instituição implementadora das normativas legais. Como todo discurso está ligado às condições histórico-sociais concretas, é possível perceber que os artigos da Constituição de 1988 que tratam do trabalho do "aprendiz" são fruto de um período de efervescência do processo de transição político-democrática, com um novo sindicalismo, com o movimento pelas diretas-já e pela anistia, assim como, de um modo geral, com as lutas pelos direitos trabalhistas, sociais, políticos e civis.

Assim, os direitos do segmento infanto-juvenil em torno do trabalho foram sendo desconstruídos e construídos, com base na visão moderna do estado de direito, do estado mínimo e da democracia participativa, no interior de discussões em todo o mundo sobre as condições de crianças e adolescentes trabalhadoras. No Brasil, essas discussões mundiais associadas às lutas sociais da década de 80 , responsáveis pelo desencadeamento de vários discursos, estão contidas 
nesse enunciado - o de que só podem trabalhar aqueles que tiverem 14 anos ou mais de idade - demonstrando que há uma preocupação governamental em favor do segmento infanto-juvenil que trabalha.

Nesse contexto, é perceptível que os enunciados legislativos estão no plano da utopia, pois não se tornaram, de fato, realidade. $O$ discurso governamental de proteção à criança e ao adolescente "aprendiz" ainda não saiu do papel; percebe-se um refluxo do mercado de trabalho no país, considerando-se igualmente o movimento das forças produtivas que determinam a economia brasileira e sua inserção no capitalismo globalizado, que impôs a existência do trabalho do "aprendiz", sem deixar deixa de ser entendido como um trabalho precoce, para, enfim, assegurar as condições de vida familiar.

\section{Conclusão}

Embora possa parecer ousada e quem sabe até superficial, a proposta desta análise foi considerar os enunciados que nomeiam o "aprendiz" em diferentes textos legislativos, cujo discurso vem sendo construído ao longo da história.

Observamos que, desde o Código de Menores (1927) até o Decreto $\mathrm{n} \circ 5.596$ (2005), a grande preocupação tem sido definir o lugar, a função e as posições de sujeito que o nomeado "aprendiz", ou criança ou adolescente, pode vir a ocupar na cadeia discursiva que permeia as relações estabelecidas.

O "aprendiz" era o "menor", pensado seja como aquele que passa, a partir de determinada faixa etária, a participar das práticas produtivas de seu grupo social, ainda que sem fins lucrativos, seja como aquele indivíduo que, através da sua inserção no mundo do trabalho, se "recuperava" do estado de delinqüência, além de contribuir para o aumento da renda familiar. Hoje, porém, no cenário atual, essa mesma palavra ganha novos contornos. Na atualidade, o "aprendiz" é o jovem cidadão que se prepara, desde cedo, para entrar no mundo do trabalho e ao qual 
se oferece uma formação técnico-profissional capaz de habilitá-lo para as atividades laborais, assim se constituindo no discurso governamental.

Há um deslocamento de sentido percebido na forma como o discurso se construiu em torno do "menor aprendiz", posto nos Códigos de Menores de 1929 e de 1979, constitutivos de um discurso que, fundamentado na filosofia menorista do início do século $\mathrm{XX}$, perdurou até o final da década de 80: discurso acatado pelo "silêncio" da sociedade da época e quebrado em 1990, porque os paradigmas pontuados nesses códigos eram opostos aos valores democráticos, liberais e jurídicos, mas em consonância com os princípios da moral, da religião, da cultura e da educação na configuração da ordem mundial.

Assim, esse discurso é ressignificado, assumindo novos significados a partir da Constituição de 1988 e do ECA, de 1990, que imprimiram ao discurso do "menor aprendiz" uma nova conotação: "cidadão aprendiz". Isso nega formalmente a base da filosofia do direito menorista. Mas esse mesmo discurso não rompe definitivamente com o discurso menorista arraigado nos fios invisíveis que perduram na linguagem formal dos seus enunciados.

Dentro desse conjunto de questões, podemos compreender as condições de produção desses discursos, imersos em conjunturas distintas: do final dos anos 20 ao final dos anos 80 do século passado se percebe que as instâncias norteadoras da discursividade em torno do "aprendiz" são fundamentadas por bases de uma filosofia do direito "minorista", no processo histórico-social cuja tendência era preservar um discurso conservador e ditatorial. Pode-se perceber que os efeitos de sentido ganham nova dimensão após a década de 1980, imprimindo nas legislações brasileiras novos efeitos de sentido ao processo de enunciação; surge, pois, um discurso com viés democrático que operou reformas para acompanhar as mudanças sociais, dando novas conotações aos processos enunciativos seja no âmbito do indivíduo, para quem os enunciados são constituídos, seja para a sociedade, que 
passa a conviver com padrões constitutivos de formações discursivas variadas.

É nesse quadro que se coloca em questão, do ponto de vista sociológico, filosófico, político e jurídico, a constituição do vínculo das crianças e adolescentes com o exercício de alguma atividade produtiva. Portanto, se os discursos legislativos/estatais, por um lado, defendem o direito da criança e do adolescente a não trabalhar, por outro, legitimam a inserção desse segmento, a partir dos 14 anos, na condição de "aprendizes", sucessores em formação. Entretanto, de "aprendizes" e sucessores em formação, eles passam a se responsabilizar pela obtenção de rendimentos para assegurar a reprodução biológica e social da família em um processo que não é de socialização, proteção, aprendizagem. Passam de participantes de uma atividade educativa, socializadora, formalmente protegida por lei, para ser apêndice dos pais ou do empregador, sob constrangimentos que os descaracterizam como trabalhadores livres. Nos fios invisíveis do discurso está a reprodução das condições penosas, pois assim se eterniza a desvalorização da força de trabalho e se operacionaliza a transmissão do legado da pobreza como um fenômeno natural.

O estado, que dá formalidade à lei, tem uma ação marginal no que compete ao cumprimento dos discursos contidos nela e faz com que a condição de "aprendiz", condição antecipada, mas legalizada, continue a reproduzir trabalhadores precoces.

Convém destacar que, na realidade brasileira, a exploração da força de trabalho de "aprendizes" segue uma tendência internacional, nos países fortemente industrializados ou em desenvolvimento, num período em que a expansão econômica passa a ser uma necessidade vital, contexto do qual emergem as políticas públicas de proteção integral a esse tipo de trabalhador (FONSECA, 2003).

Assim, com base nos pressupostos da AD, tomamos os enunciados legislativos como objeto de análise 
e pudemos perceber que os sentidos constitutivos desses enunciados se concentram em uma unidade complexa de significações que nasce das necessidades pontuadas num processo histórico-social e culmina no processo ideológico. Entendemos que os textos legislativos e seus enunciados possuem um sujeito histórico determinado nesse processo, cujos enunciados atendem à dinâmica desse sujeito, mesmo não sendo ele interlocutor do discurso, mas constitutivo do centro para o qual os discursos convergem. 


\section{Referências}

BAKHTIN, M. Estética da criação verbal. São Paulo: Martins Fontes, 1992.

. Marxismo e filosofia da linguagem. São Paulo: Hucitec,

1999.

BRASIL. Decreto Lei n5.596, de 1de dezembro de 2005. Regulamenta a contratação de aprendizes e dá outras providencias.

CONSOLIDAÇÃO DAS LEIS DO TRABALHO - 1943.

CARRION, V. 29. ed. São Paulo: Saraiva, 2004.

COSTITUIÇÃO DA REPÚBLICA FEDERATIVA DO BRASIL 1988. PINTO, A. de T. (et al). 27. ed. São Paulo: Saraiva, 2001.

ESTATUTO DA CRIANÇA E DO ADOLESCENTE. Lei n. 8.069/1990. Julho, 1990.

FONSECA, J. C. de F. Adolescência e trabalho. São Paulo: Summus, 2003.

LACLAU, E.; MOUFFE, C. Pós-marxismo sin pedido de disculpas. In: LACLAU, E. Nuevas reflexiones sobre la revolución de nuestros tiempo. Buenos Aires: Nueva Visión, 1990.

ORLANDI, E. As formas do silêncio: no movimento dos sentidos. Campinas: Editora da Unicamp, 1992.

Análise de discurso: princípios e procedimentos.

Campinas: Pontes, 2001.

PÊCHEUX, M. Semântica e discurso: uma crítica à afirmação do óbvio. Campinas: Editora da Unicamp, 1988. 